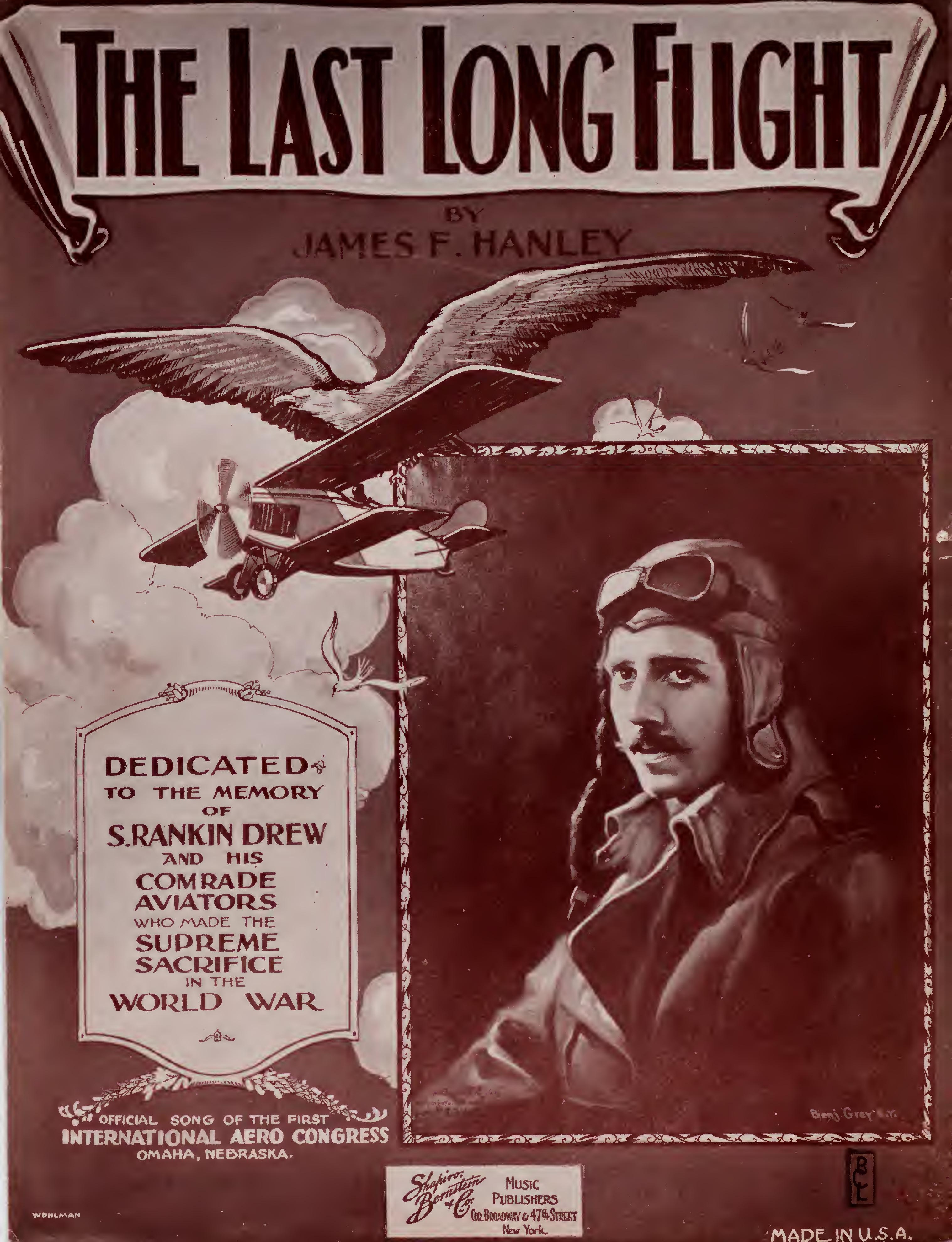




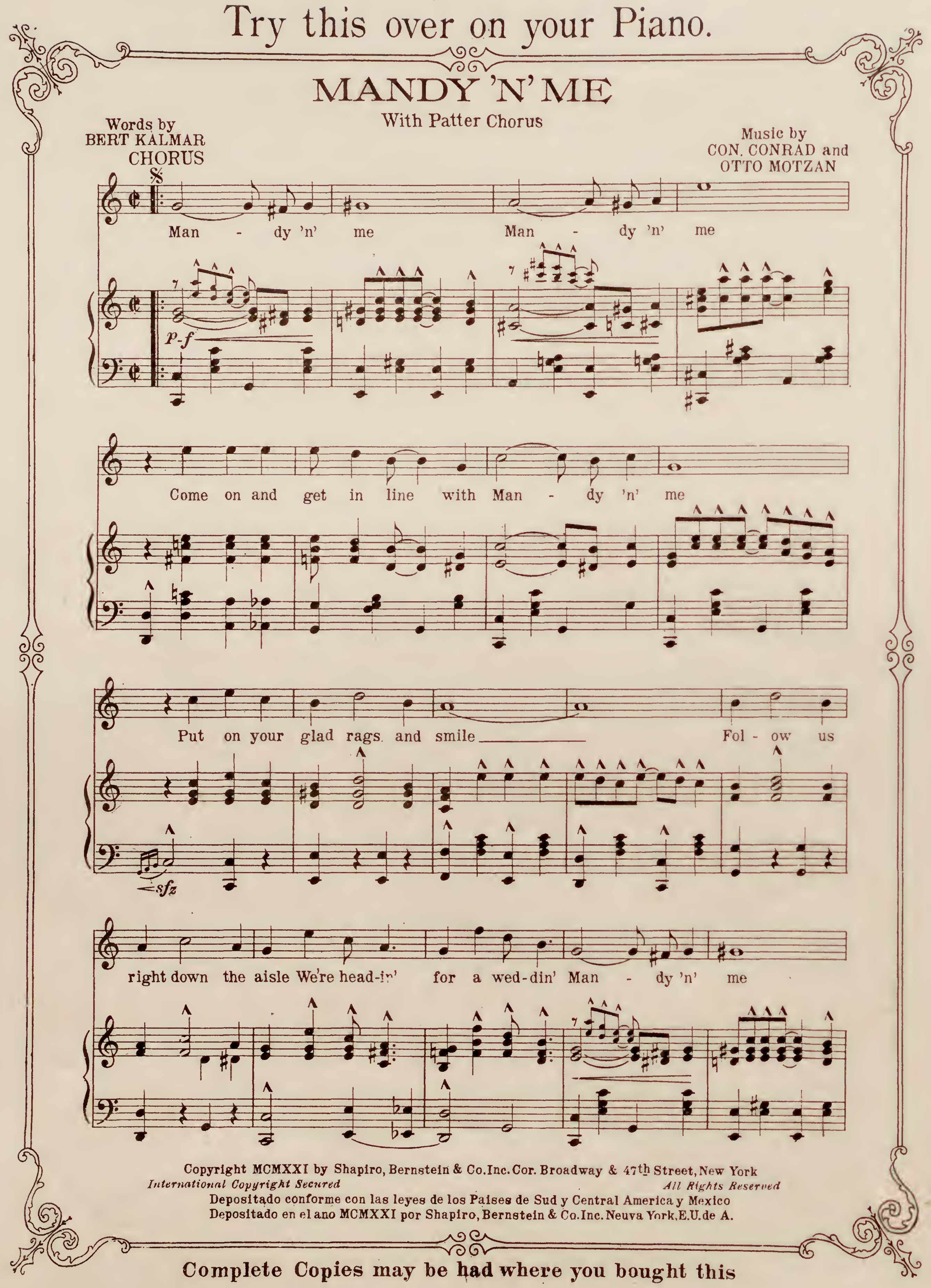




\section{The Last Long Flight}

By JAMES F. HANLEY
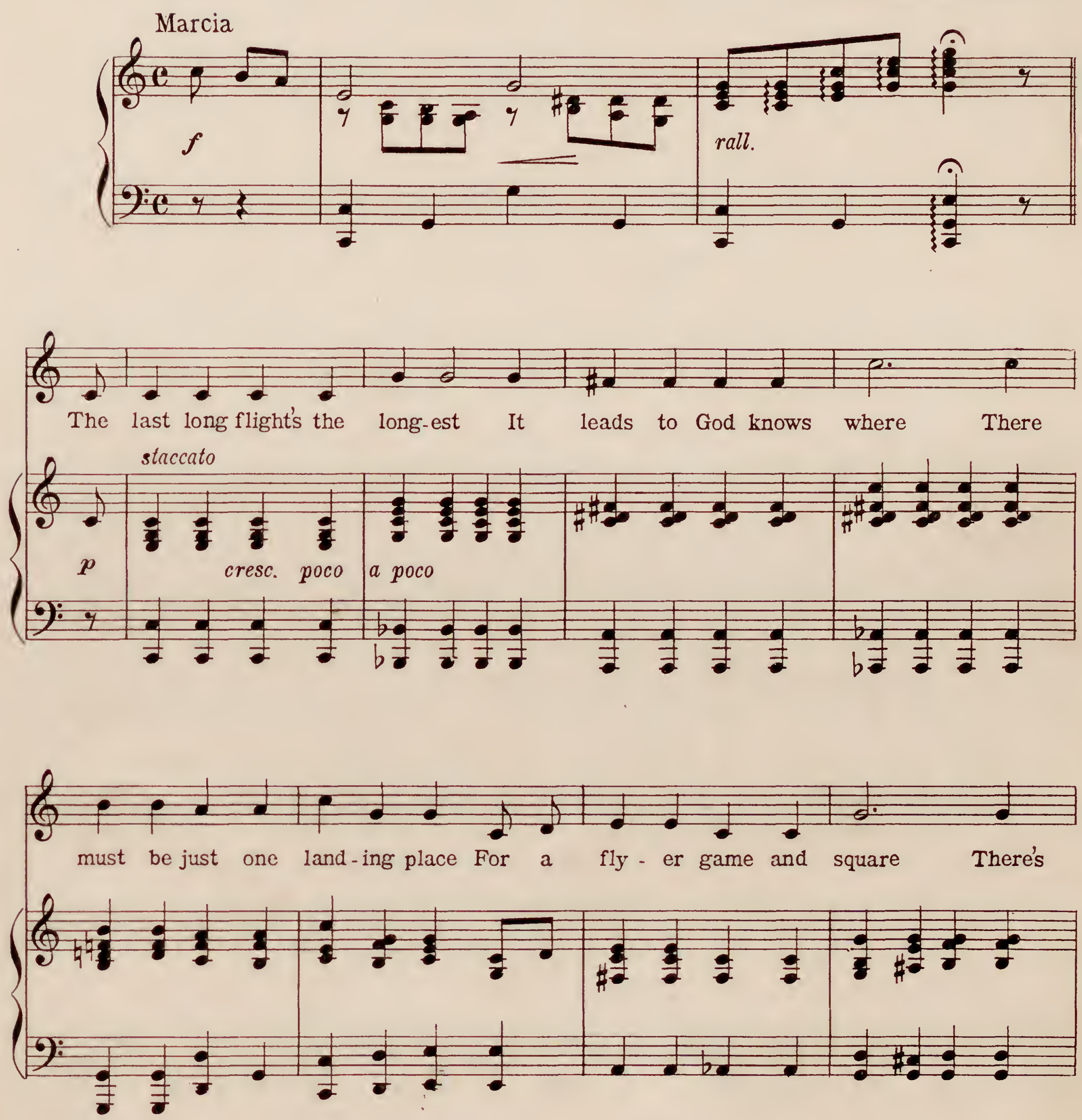

Copyright MCMXXI by Shapiro, Bernsteln \& Co. Inc. Cor. Broadway \& 47 th Street, New York International Copyright Secured

All Rights Reserved

Depositado conforme con las leyes de los Palses de Sud y Central America y Mexico

Depositado en el ano MCMXXI por Shapiro, Bernstein \& Co. Inc. Nueva York, E.U.de A. 


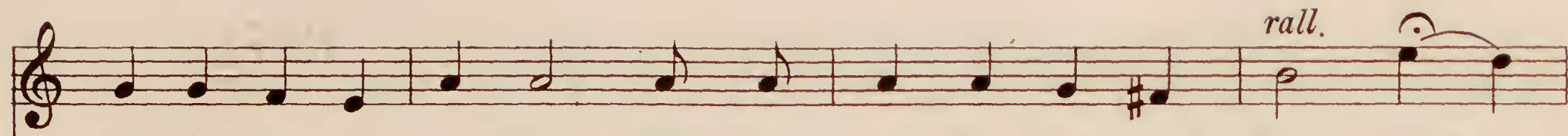
on-ly one di - rec-tion When he says his last good - bye And -

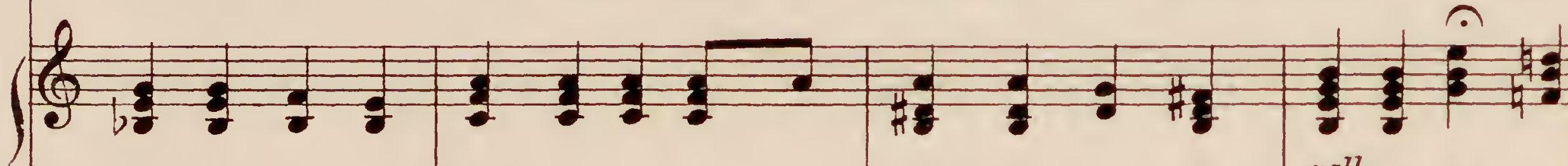

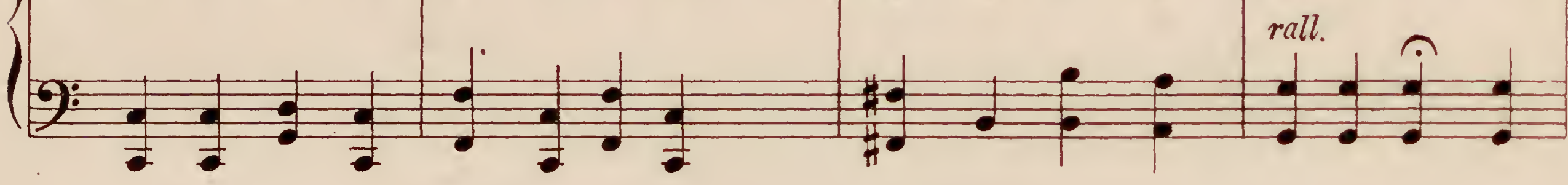

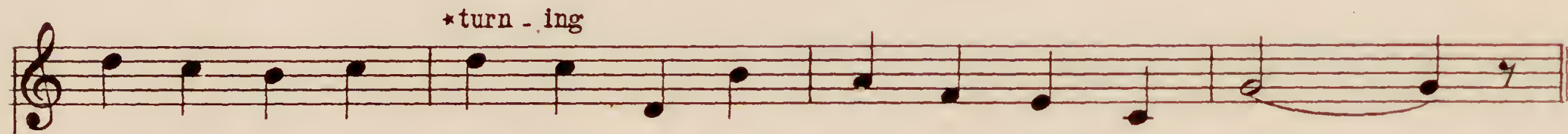
gets his mo-tor "rev-ving For his trip be - yond the sky.

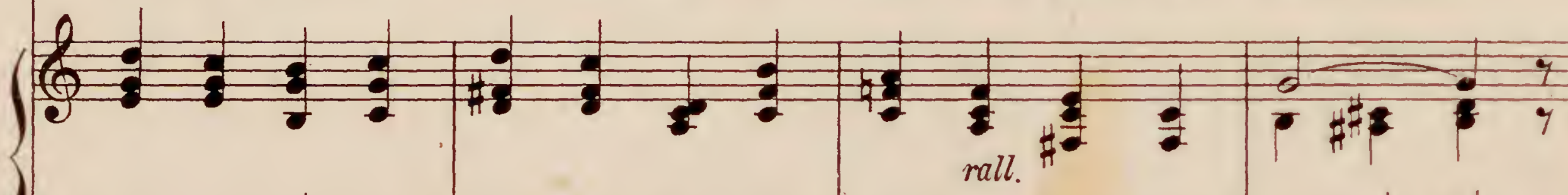

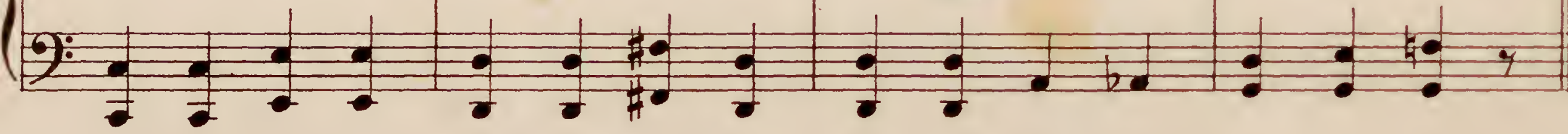

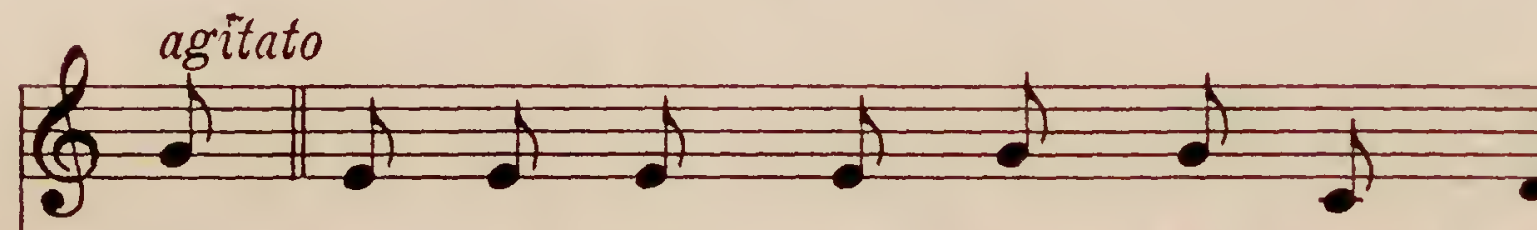

His spi - rit plane goes climb-ing toward the stars

The

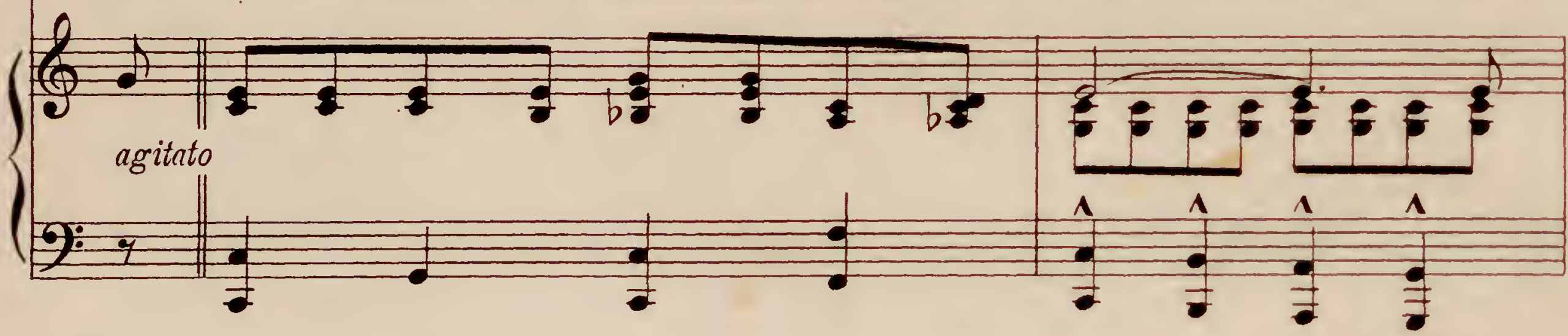

$(2)+2$ new moon tips his wings with sil - ver light

The

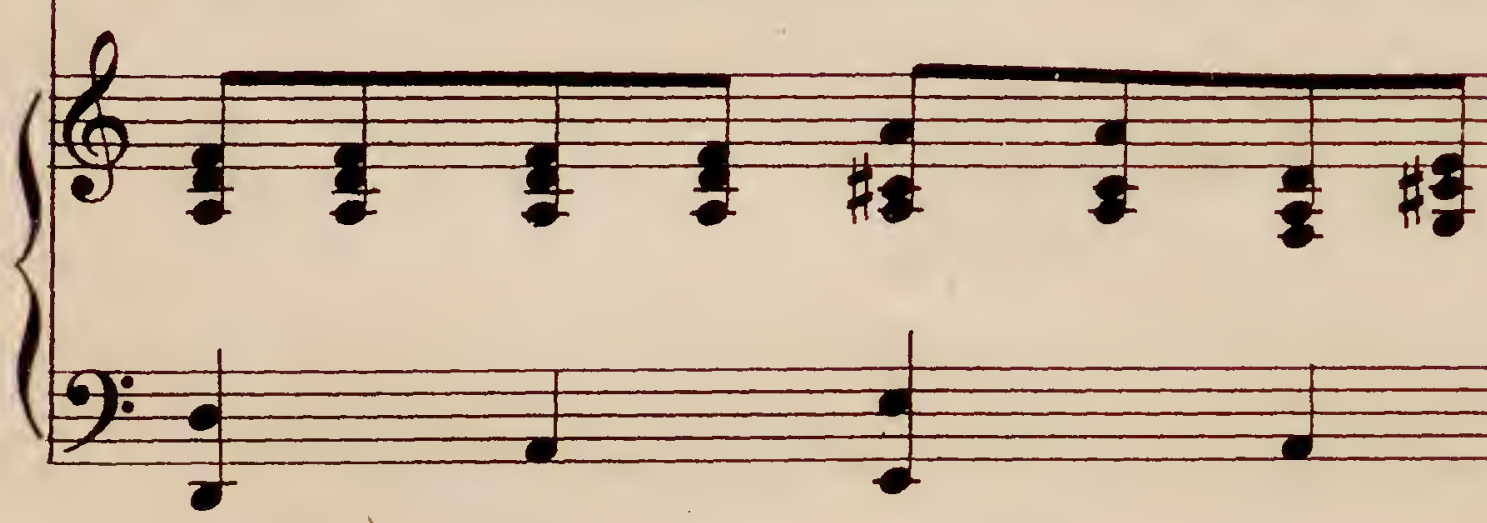

The Last Long Flight-3

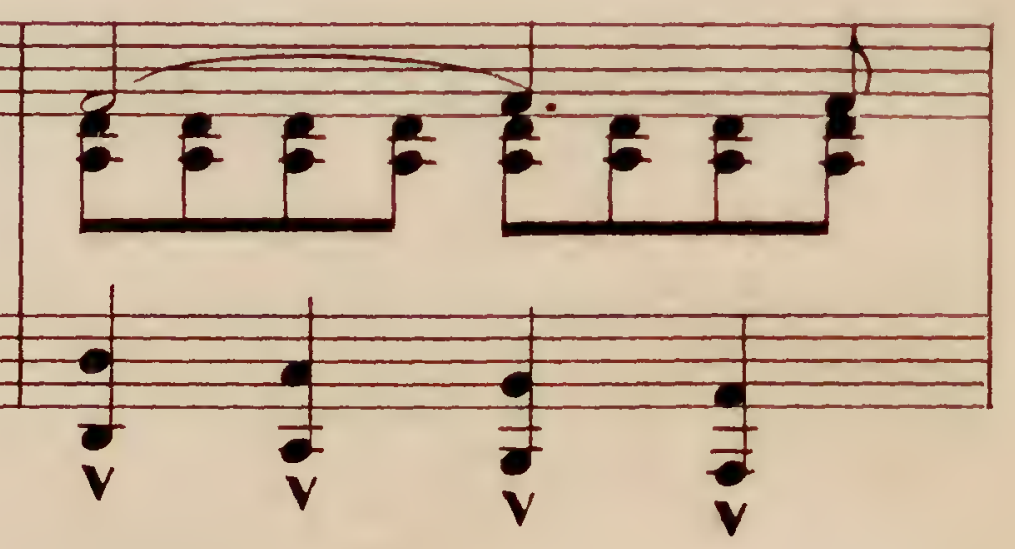




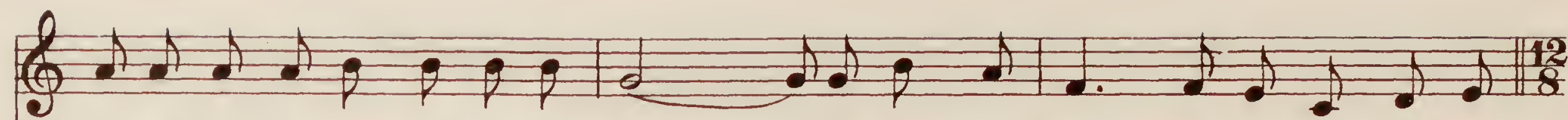
An-gels wait a-round his han-gar door___ To watch him land and wel-come him that

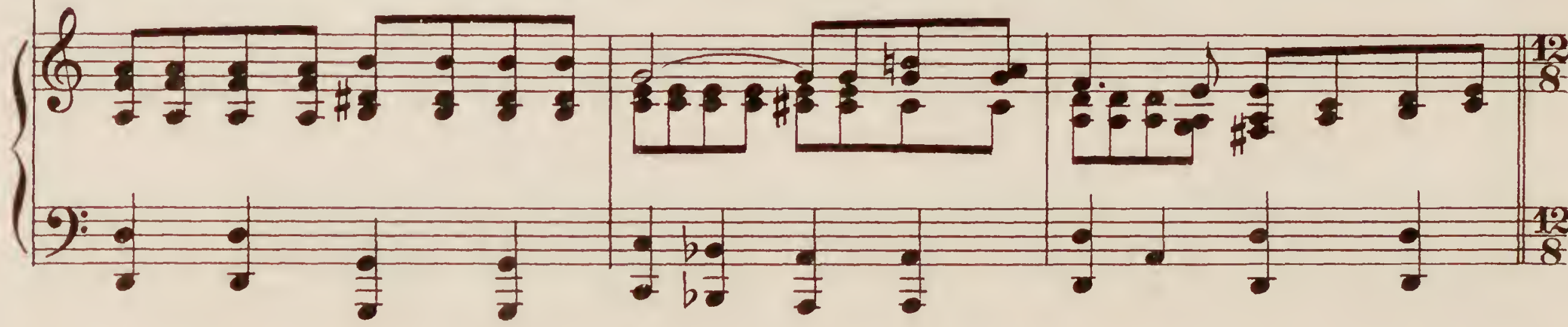

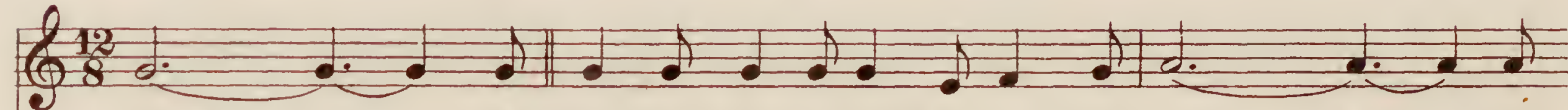
night___ His eyes grown wea-ry watch-ing soon find rest___ Soft

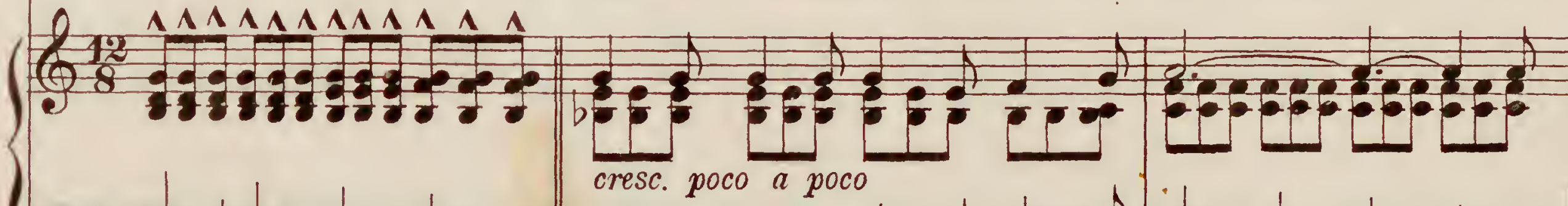

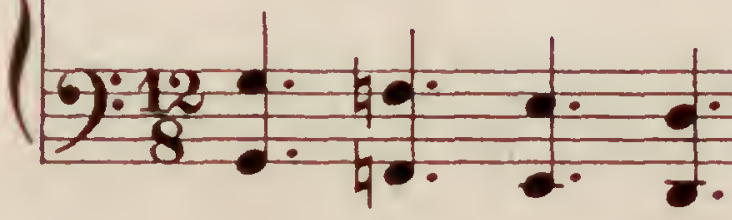

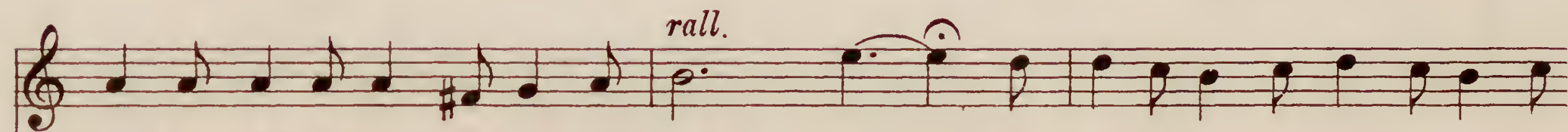

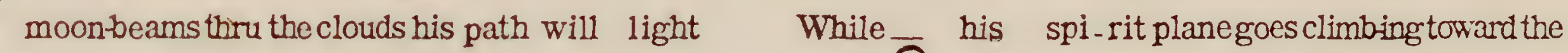

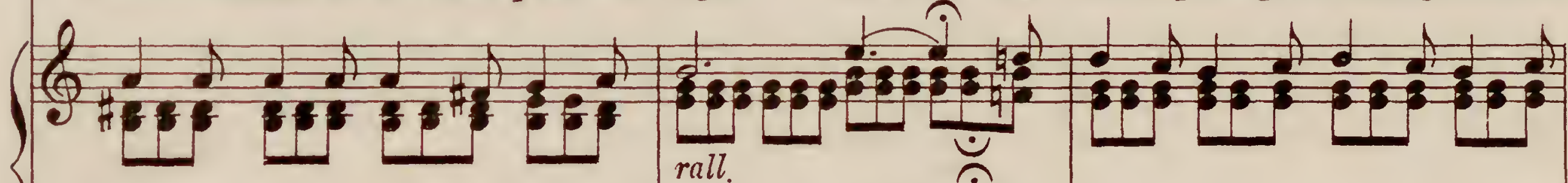

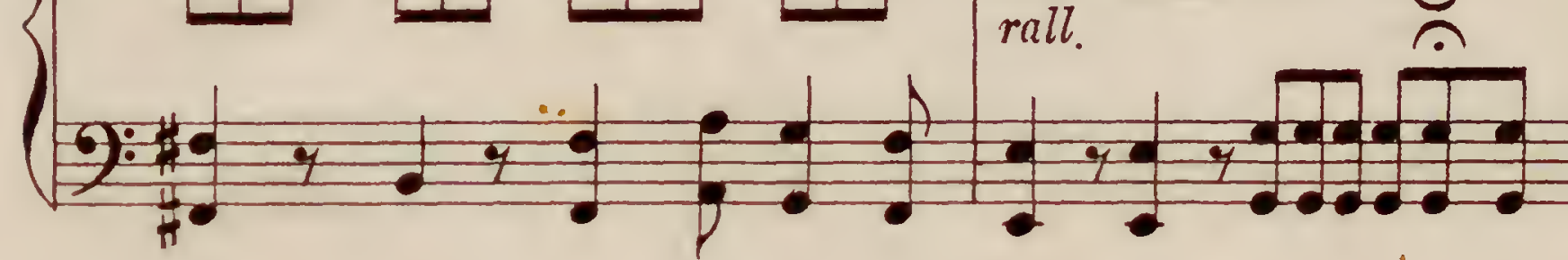

Andante

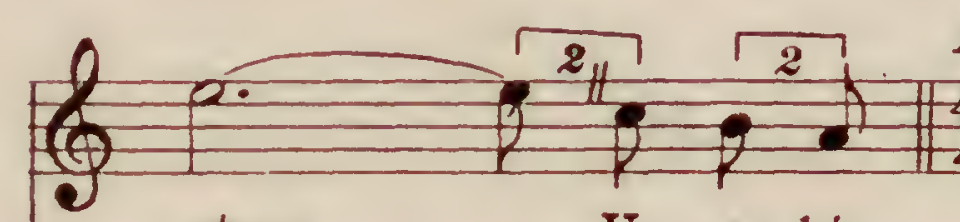

stars

Up - on his

last

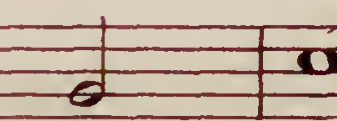

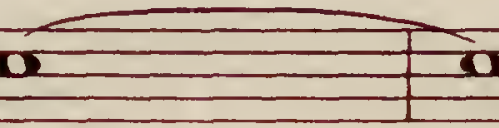

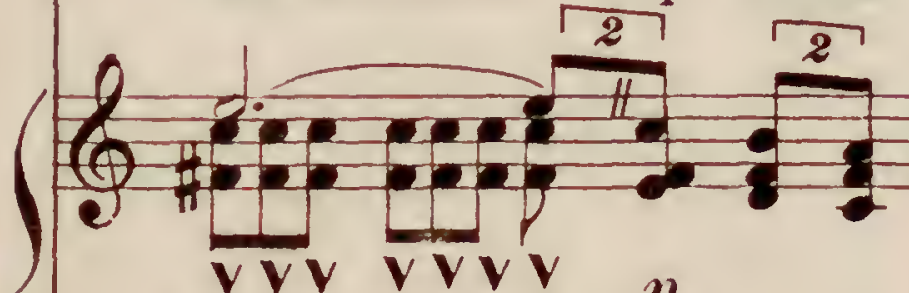

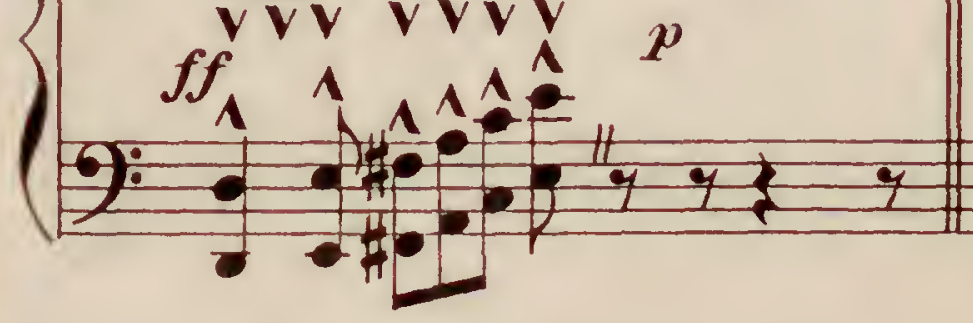

Andante

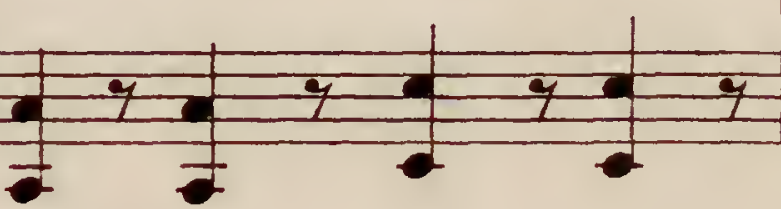

The Last Long Flight-3

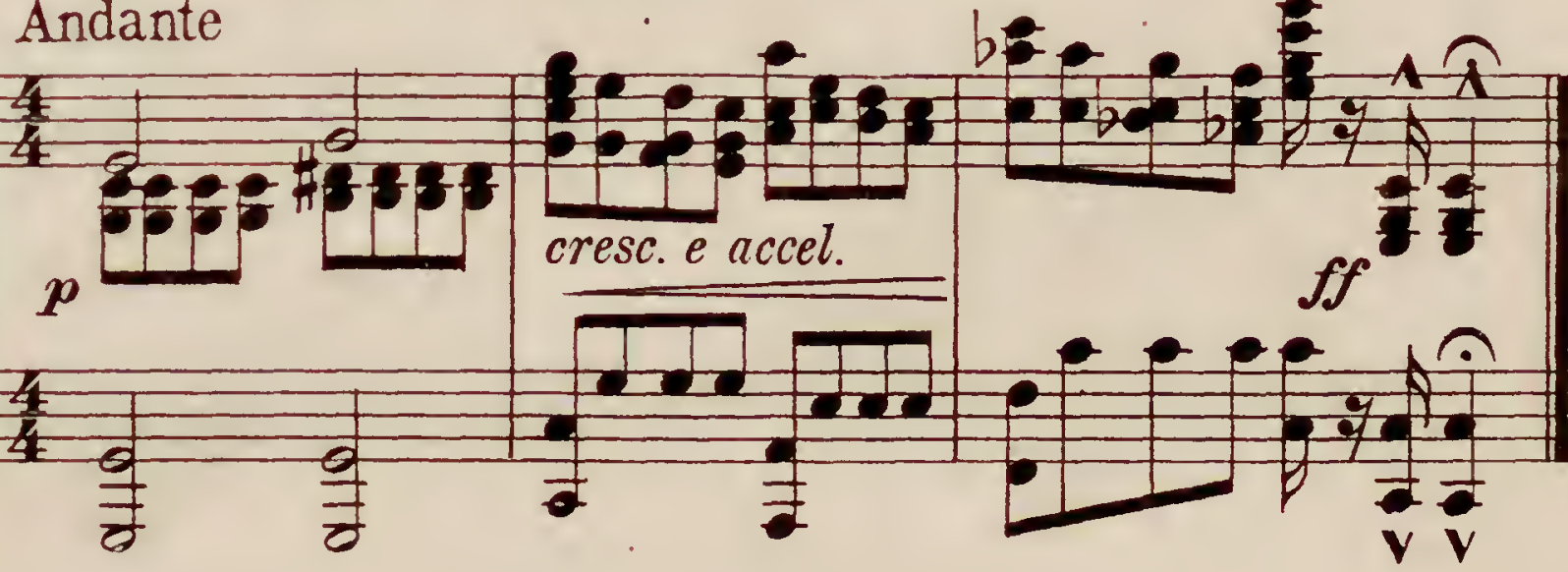


BROADWAYS MUSICAL COMEDY SUCCESSES 等 1.2) Sols $\int^{0}$

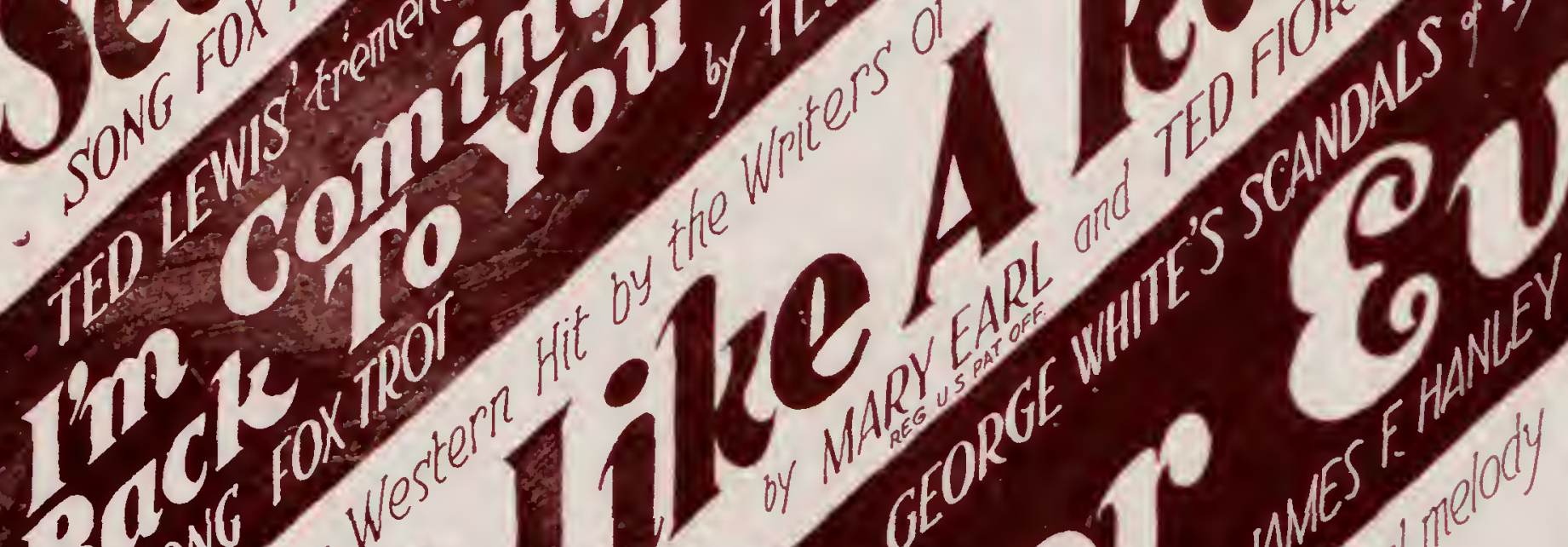
30,0 we 1) 50.13019

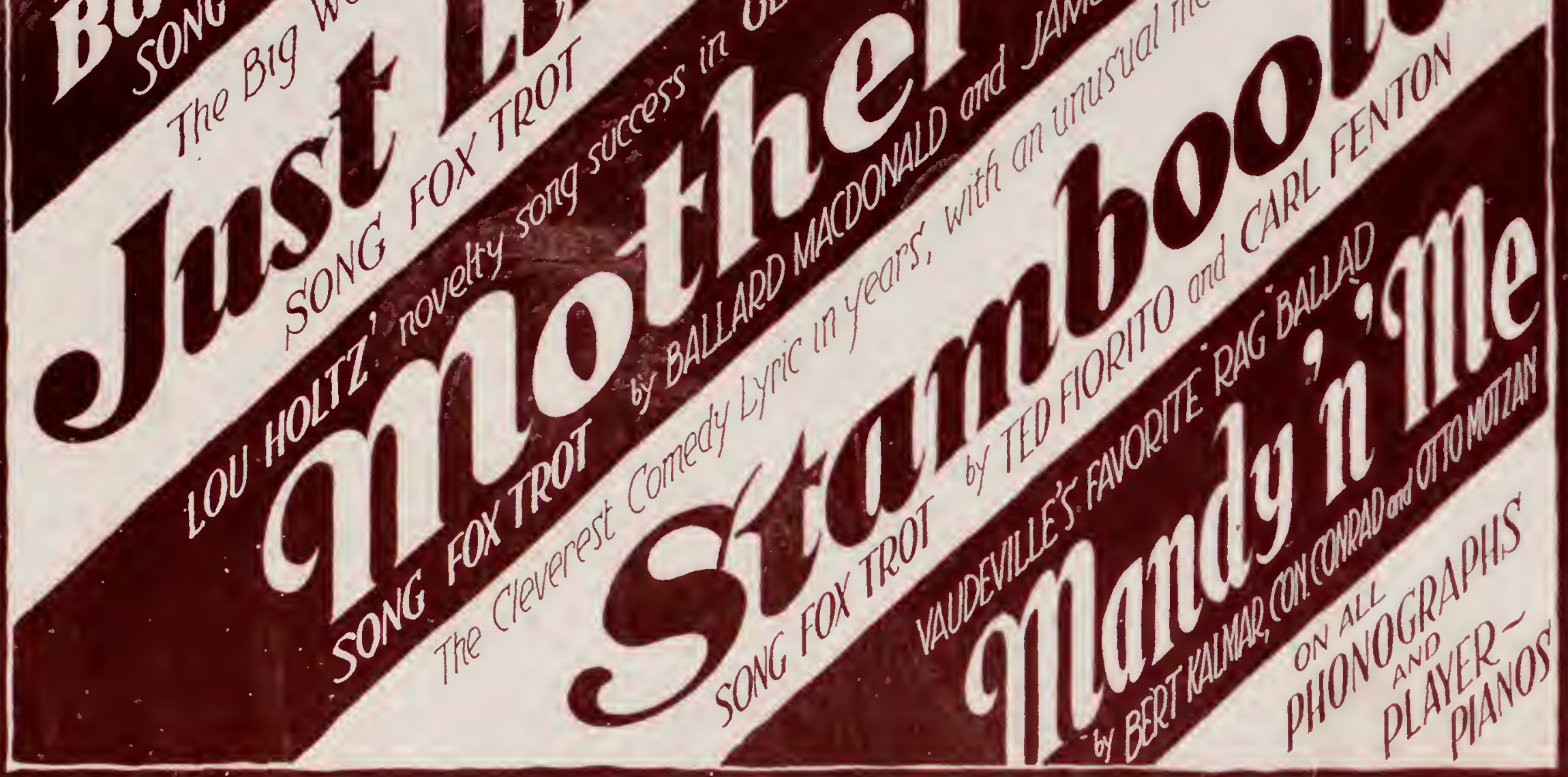

ALL THE LATEST SONG HITS IN DANCE FORM

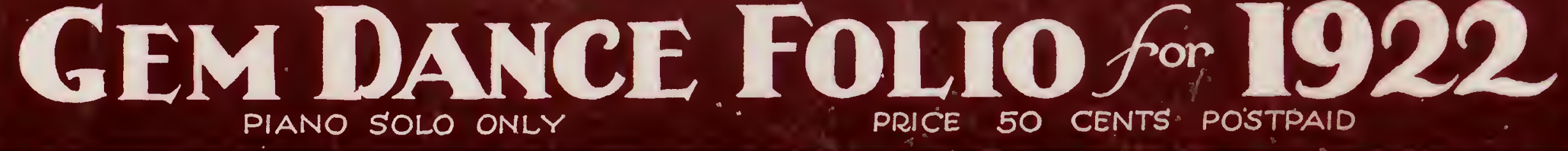

